\title{
Taming the Beast. Approaches to Digital Archiving in Czech Archaeology
}

David Novák, Martin Kuna and Olga Lečbychová

\section{Summary}

As in other countries, Czech archaeology has embarked on a journey of digitisation. This creates the need to cope with the rapid growth of digital data, which must be stored securely over the long term and be accessible in a comprehensible and useful way. This causes several problems. Although there is a centralised and well-resourced digital agenda that meets the requirements of the Heritage Law, outdated legislation and the absence of comprehensive rules do nothing to regulate the management of the most valuable data - the primary documentation of fieldwork events. At present, only summary information on archaeological fieldwork and the final reports, which should contain a substantial selection of documentation, are centrally collected and stored. This is a situation that is difficult to accept as primary (raw) data with a greater information value is disappearing into thin air. The premise for change lies in supplying the existing central infrastructure - The Archaeological Information System of the Czech Republic (AIS CR) with the tools to acquire and archive primary data on a larger scale, while at the same time, amending the legal obligations imposed on archaeological practitioners.

Sustainable change requires a significant overhaul of the current concept, objectives and especially the practice of archaeological fieldwork projects, particularly in the planning and post-excavation phases.

\section{Introduction}

The archiving of data in archaeology is linked to the conceptual and organisational framework of data collection and the competences of the various actors who enter this process (Perrin et al. 2014). Archaeological fieldwork in Czechia has undergone a long evolution over the past century - from being exclusively organised by a central state institution to the 'free market' environment of today. The increasing digitisation of administrative and research processes poses challenges to deal with both the existing archives and the collection of new data. This text summarises the situation and the core problems preventing Czech archaeology from being fully 'FAIR'. Paradoxically, the problem does not lie in the digitisation itself, but in the organisation of the fieldwork 

state of affairs.

\section{Framework of Archaeological Archiving in Czechia}

Archaeology developed in Czechia from the beginning of the 19th century. Soon after the creation of Czechoslovakia (1918), the State Archaeological Institute (1919) was established as the first professional institution engaged in theoretical research and the systematic management of information on the national archaeological heritage. Both tasks were gradually transferred to its successor organisations, which are now the two separate Institutes of Archaeology of the Czech Academy of Sciences (in Prague, IAP, and Brno, IAB; cf. Kuna et al. 2015).

The current role of the Institutes in the system of archaeological heritage management is influenced by this tradition and anchored in the State Heritage Management Act (No. 20/1987 Coll.), which appoints the Institutes as the only organisations authorised to conduct archaeological fieldwork. The opportunity for other organisations to conduct fieldwork is conditional on a licence from the Ministry of Culture and an agreement with the Academy of Sciences. Archaeological Institutes are mandated to collect information on fieldwork from all the entities involved in the process. However, the law does not specify any details of this, and the state does not yet directly provide the Institutes with any funding for it. Although archaeology in Czechia should be non-commercial by law, in practice it is part of a fully commercialised environment led by free competition for contracts. At the same time, due to vaguely defined regulations, there is no body appointed for the quality control of the fieldwork. Institutes of Archaeology are expected to play this role to some extent; however, their capacities, as well as the enforceability of their decisions, are extremely limited. From the perspective of both the IAP and the IAB, the law passed in 1987 is clearly no longer conceptually viable and in a free-market environment is largely dysfunctional.

To a certain extent, the task of the Archaeological Institutes to conduct archival work contradicts their main mission, i.e. scientific research. Until recently, this contradiction was overcome by the concept of archives as a research tool: Institutes built archives for their own use (although, of course, they were always open to the entire research community). This model has fundamentally changed in the last 20 years; in our opinion, it has become clear that (a) Czech archaeology as a whole needs a central information infrastructure for the scope of research and heritage management, (b) the development of a digital infrastructure is a more complex task than simply gathering printed documents, and (c) the Institutes of Archaeology are currently the only institutions in Czech archaeology capable of conceptually, organisationally and technically mastering it. The connection of the digital infrastructure to research institutions has proved advantageous, if not necessary. However, Czech archaeology is still waiting for a clear legislative step to change the current state of affairs - various versions of the relevant law or amendments have previously been presented to the Czech Parliament over the past 20 years but have never been approved. 


\section{Developing Approaches to Research and Archiving}

\subsection{Period of 'academic' archaeology (until 1989)}

Before the fall of the Iron Curtain in 1989, the concept of fieldwork as a research activity leading to knowledge of the past prevailed in Czech archaeology. Archaeologists were convinced that finds were primarily (if not only) information and de facto their property. Extensive long-term ('systematic') excavations were conducted to obtain basic research data. The analysis and publication of such data were completely left to the authority and responsibility of the project director. The undesirable results can be illustrated by the amount of hitherto untreated, confusing, or lost data from large fieldwork projects. Neglecting primary documentation was common practice and the notion of archaeological fieldwork as a form of heritage management was promoted only very slowly (e.g. in the practice in the IAP's Branch Office in Most, associated with surface coal mining). Since the 1960s, field activities of the Institutes (and later other organisations) were at least briefly reported in annual summaries (Bulletin záchranného oddělení, Přehled výzkumů). Due to the centralisation of research, there was at least a basic control over the emerging primary documentation, which was usually handed over to the IAP and IAB archives. Such a context made it possible to gradually convert these documents into digital form, organise them and systematically publish them online. The lack of evaluation of important fieldwork can thus be conducted ex-post based on primary documentation, although the value of such research is variable.

\subsection{Period of 'rescue' archaeology (1989- 2002)}

Since the end of the 1980s, the concept of fieldwork as archaeological heritage management began to prevail over the instrumental research-orientated approach. Archaeological heritage has been recognised as a value by itself, although exhaustible and irrecoverable. Systematic excavations were closed, and Czech archaeology focused entirely on rescue projects, which exploded in numbers due to the building boom of the 1990s. However, as a consequence of social change, archaeology was hit by the free market. By the decision of the post-communist directors, the Archaeological Institutes, until then organising major fieldwork events, have substantially reduced their activities, separating individual regional branches from them. At the same time, a number of private units dedicated to archaeology were created, applying the statements of a still relatively new Heritage Law in a way in which it was never meant to be used in the framework of a socialist state. The hitherto centralised system expanded to include dozens of newly licensed organisations, which took advantage of a generally lowregulated environment and entered the field, often with enthusiasm but variable quality. Rescue field projects quickly became a commercial activity, hence incompatible with the original ideas behind the new approach. The ambiguity of the legal environment, an increase in the number of private and semi-private archaeological organisations, and the 
low capacities of the Archaeological Institutes to channel this process, led to a chaotic and often sloppy development.

To address this situation, the IAP archive concentrated on building up a central database of fieldwork activities that processed both the various retrospective data sources and new fieldwork data to create a comprehensive digital record of Bohemia (the western part of Czechia covered by the activities of the IAP). This created the Archaeological Database of Bohemia (ADB; Kuna 1994; 2002), which attempted to identify all known fieldwork events and describe the results within an elaborated metadata system. The IAB created an internal database for the territory of Moravia and Silesia, mostly applying the ADB system to enable future compatibility. Although the actual emerging data was selectively registered and the primary documentary archives are still stored in the relevant parent institution or are currently unknown, via ADB the foundations of the digital information systems were laid. The ADB data model proved essential and its basic concept of the 'archaeological fieldwork event' remained the core record unit of all the subsequent versions of the archaeological data infrastructure in Czechia.

\subsection{Mass digitisation period (2002-2012)}

A breakthrough in the development of digital resources was brought about by the flooding in Prague in 2002 when the IAP's archive was significantly damaged. A similar effect was initiated by the fire in the archaeological base of Mikulčice in 2007, where an archive of IAB's systematic excavations was stored. These catastrophes showed what archaeology could easily lose and opened the eyes of the archaeological community in this respect. It was admitted and accepted that archaeological finds and data are neither just tools for knowledge acquisition, nor a means to make a financial profit, but cultural values that need to be preserved for the future. The programme for the systematic digitisation of archives and the first Digital Archive application were launched and the readiness of the staff to deal with digital data increased. The Internet Database of Archaeological Fieldwork (IDAF) was implemented in 2007 as the first coordinated entry of the Archaeological Institutes into the organisation of fieldwork and the first tool that functioned for the whole of Czechia. During the same period, IAB introduced the Digital Archive and Evidence of Archaeological Excavations in Moravia and Silesia (DAEAE) to store data for the relevant regions and to close the gap that had formed between the IAP and IAB approaches to archiving.

\subsection{Period of systematisation (post-2012)}

The emergence of ADB, Digital Archive, IDAF and DAEAE has paved the way to the (so far) final step in the digitisation process, which began in 2012 with the Archaeological Map of the Czech Republic (AMCR) project. This information system integrated all available sources in one database, unified access via an online application and set new rules on the information flow in Czech archaeology. The Archaeological Information System of the Czech Republic (AIS CR) was established as the overarching framework in 2016, linking the IAP and IAB activities with a common organisational background. The AIS CR was soon included in the Roadmap of Large Research Infrastructures adopted by the Government of the Czech Republic, making it the national authority in the field. The first real success of AIS CR was the launch of the AMCR in 2017 and the 
subsequent launch of many freely available digital services (AIS CR; Kuna et al. 2015; 2019).

With the advent of digital methods, the problem of data management continues to grow, with insufficient equipment and low ICT competence among researchers. In Czechia, there are currently two data repositories with a valid CoreTrustSeal certification, but these are focused on the areas of linguistics and social sciences (CoreTrustSeal). Therefore, although the AIS CR infrastructure is yet to pursue certification, there is no viable alternative for archiving archaeological data. This is supported by the position of the Ministry of Education, Youth and Sports on the implementation of the EOSC in the Czech Republic, which states that the large research infrastructures are considered the basic pillars and means to apply the FAIR principles in academic practice

(Trtílková 2020).

\section{Current Archiving Workflow}

In Czechia, 111 entities are licensed to conduct archaeological fieldwork, comprising 82 museums, 16 non-profit organisations, 7 universities and 6 public research institutions. These organisations operate under the 'polluter pays principle' (with a few exceptions) and archaeological finds are defined as public property managed by the county or the state. As fieldwork licences are only granted to organisations for selected regions, the quality and nature of both the research and the documentation vary considerably depending on which organisations operate in the region. The data from the regions show that there are significant differences not only in the number of reported field interventions per capita (Figure 1) but also in the level of processing. The situation is usually better in districts with a well-functioning Regional Archaeological Commission and strong representation of public institutions (regional museums, heritage institutes, etc.). 


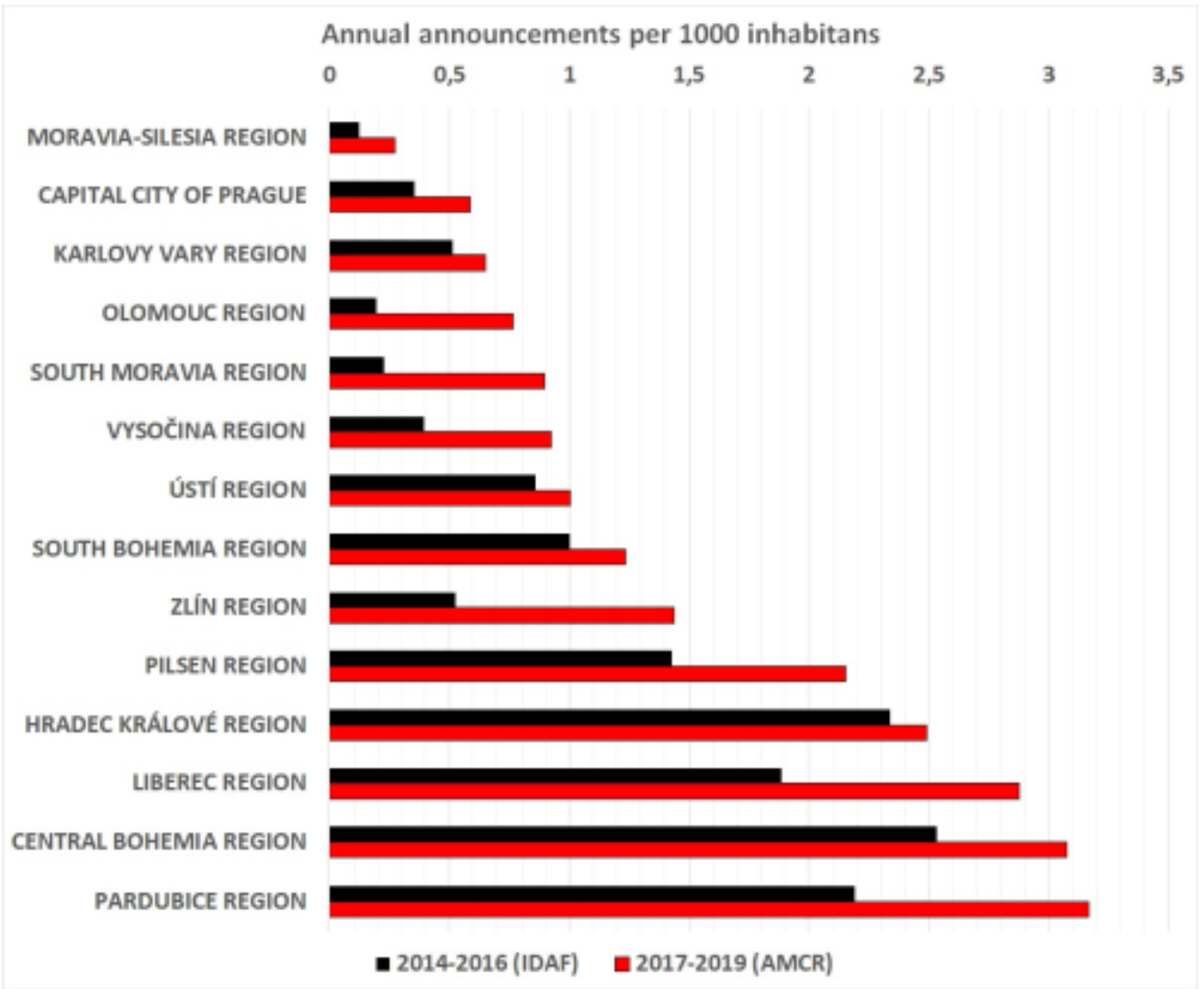

Figure 1: The number of field intervention notifications by region based on the AMCR data. The comparison of sub-periods suggests a positive trend in coverage rates across regions, but also significant differences in archaeological heritage care performance. Created by D. Novák.

Practically, the following stages are distinguished in the administration of fieldwork and data creation.

\subsection{Field intervention notice}

Anyone planning to carry out construction or other activities in an 'area with archaeological finds' (in practice, the whole of Czechia) is obliged to notify one of the Archaeological Institutes of this intention. The notices are collected via an online form, which is directly linked to AMCR. Each entry is given a permanent identification and recorded as an 'archaeological project', which may reach (but need not) the implementation phase. Currently, the annual number of projects is c.18,000 and is increasing steadily. At the moment, this covers about $70 \%$ of the building and development projects that may appear archaeologically relevant.

\subsection{Registering a fieldwork project}

Under a contractual agreement, each licensed organisation has access to the digital project register in the AMCR where it can obtain information about the planned development and 'register' them to conduct fieldwork. Following this, the organisation can contact the notifier and enter into negotiations to conclude a contract to conduct an archaeological intervention. The practice of distributing fieldwork opportunities varies 
regionally. Regional Archaeological Commissions, which organise research activities, play a strong role whereas in other regions the process is left open to the organisations' market behaviour. Unfortunately, registering a 'project' does not require any formal document to be prepared (project in the sense of a 'feasibility study'). The absence of such a document precludes any efficient control of the project quality and the adequacy of the conditions for both the project initiator and the archaeologist. Thus, there is no single document that captures the life cycle of primary data and the process is based on established practice in the organisation or the expertise of a particular researcher.

\subsection{Notice of commencement and termination of fieldwork}

The next obligatory step to be reported in the AMCR is the announcement of the commencement and termination of archaeological field activities, from which a threeyear deadline for submitting the final report begins to run. However, sometimes the dates are reported ex-post, as the law does not set any time limits, nor does it provide any penalties for breaching this obligation. Again, the absence of a formalised project plan precludes the project from being meaningfully audited during its course; apart from that there is currently no relevant authority expected or obliged to provide such an audit.

\subsection{Submitting the report on fieldwork results}

The main output of any archaeological field activity in Czechia should be, in the dictum of law, the 'fieldwork results report' (\$21, par. 4 of Act No. 20/1987 Coll.). Although the form of the report is not given by the law, the Archaeological Institutes, based on longstanding practice, set standards through agreements with licensed organisations. By these standards, the report (traditionally called the 'Excavation Report', hereinafter ER even in cases when other types of field activities are concerned) has a fixed structure and content. The ER should be delivered to the archives of one of the Archaeological Institutes (IAP for Bohemia, IAB for Moravia and Silesia). The ERs are collected independently of the processing and transmission of movable finds, which usually go to regional museums, mostly at a much later date. This discrepancy makes it logistically difficult (or almost impossible) to keep the link between an ER and the corresponding finds.

None of the relevant regulatory documents refers to primary field documentation and its existence as such is formally disregarded. Therefore, as the ER is only an official result passed to the archives, it is composed as a summary of the fieldwork results with all the relevant primary documents. In the traditional (non-digital) concept, it is a meaningful solution - in practice, these were large, printed files containing a representative selection of raw data (including planning and photographic documentation) accompanied by a description and basic interpretation. From the 1990s, a brief structured summary of fieldwork circumstances and results (the so-called 'Fieldwork Event Report') was also required as part of the ER, which was used as entries to the ADB. Today, the FER is submitted as a metadata record in the AMCR and the ER is attached as one or more PDF files through the AMCR application.

The problem is that preparing an ER is a long and challenging process, especially for large-scale excavations. Archaeological projects only partly account for the cost, and the 
competitive market environment does not allow for a reasonable increase in funding. Although an FER is usually handed over, there is far from always a complete ER. Usually, the larger and potentially more important the fieldwork undertaken, the less likely the delivery of an ER in time (if at all). Even worse, the primary field documentation mostly remains outside the control of the Archaeological Institutes and may become unavailable or lost. AMCR, as a comprehensive digital tool, brought new possibilities to control the fieldwork workflow. It is possible to find out which ERs are missing and who was responsible for their delivery. However, this tool can only be fully applied to fieldwork events registered since 2017 and does not solve the problem of settling past debts. Although IAP and IAB devote considerable effort to tracing down the unreported field activities and obtaining the relevant data, many ERs will probably never be finished.

\subsection{Validating and publishing the data}

After submission of the FER and ER into the AMCR system, a formal, technical and content review is conducted by the Archaeological Institutes' archivists. After validation, FER and ER are published via the AMCR Digital Archive online service and AIS CR

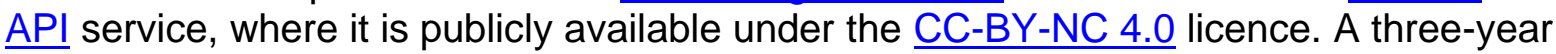
embargo period is applied to new reports, which can only be accessed upon request and the consent of the author. After this deadline, most of the data are open to any registered user (except non-licensed reports and sensitive data on sites at risk of illegal activities). Again, this publication procedure has no basis in law but is the result of a long discussion moderated by the AIS CR infrastructure (summarised in Kuna and Tryml 2018).

ER is a copyrighted work from the point of view of the Czech Copyright Act and publication is not possible without the consent of the rights-holder (usually the creator's organisation). Therefore, after significant negotiations, licensing agreements with individual data providers had to be concluded to publish the data. Finally, AMCR data can then be provided according to the FAIR principles - it is findable (due to FER metadata), accessible (through the Digital Archive), interoperable (due to AIS CR's public API) and reusable (due to uniform processing in the AMCR and clear licensing). To date, 81 organisations have signed licence agreements and more than $90 \%$ of the archived documents are openly accessible. The remainder are searchable and available upon request, which is individually considered and (if needed) the copyright holder is consulted. The same applies to legacy archive documentation, which is inserted retrospectively into the Digital Archive after digitisation.

\section{How Far are we from the Digital Dark Age?}

Between April and July 2020, a questionnaire survey was conducted by the AIS CR team among the organisations managing archaeological archives to recognise their volumes, status and handling (i.e. the potential level of threat to them). Of the 169 institutions or their organisational units contacted, $114(70 \%)$ responded, which represents a reliable reflection of the overall situation. Some preliminary results of the survey are presented here. 
It has been shown that the volumes of data collections differ significantly in individual organisations - in the case of text documents, typically hundreds to thousands of documents are stored (42\% of the organisations have up to 100 documents, and $55 \%$ of them archive 100-5000 documents), and in the case of photographs, the numbers increase (37\% up to $1000 ; 51 \% 1000-50,000$ images). For maps and plans, the numbers are similar to those of texts (47\% up to $100 ; 46 \% 100-5000$ maps and plans). Specific types of documents, such as scientific reports (77\% up to $100 ; 20 \% 100-1000)$ or aerial photographs (83\% up to $100 ; 10 \% 100-1000$ images) can also be included. Other data types make up a negligible component of archives (legacies, card records) or are not directly relevant to primary documentation (inventory and registering books).

Table 1: Accessibility of archive collections in individual archaeological organisations based on data from a questionnaire survey. Figures show the proportion of institutions making the collections accessible in a way as specified. Compiled by D. Novák

\begin{tabular}{llllll} 
& textual & field photos & $\begin{array}{c}\text { maps } / \\
\text { plans }\end{array}$ & aerial images expert data \\
\hline unavailable & $6 \%$ & $8 \%$ & $14 \%$ & $53 \%$ & $18 \%$ \\
inaccessible & $3 \%$ & $12 \%$ & $10 \%$ & $13 \%$ & $10 \%$ \\
on-site on demand & $89 \%$ & $79 \%$ & $80 \%$ & $75 \%$ & $81 \%$ \\
on-site freely & $1 \%$ & $1 \%$ & $1 \%$ & $4 \%$ & $1 \%$ \\
digitally on demand & $23 \%$ & $25 \%$ & $23 \%$ & $17 \%$ & $18 \%$ \\
digitally freely & $1 \%$ & $0 \%$ & $0 \%$ & $2 \%$ & $1 \%$
\end{tabular}

Most organisations (54\%) characterise their collections as unprocessed. Only $24 \%$ of organisations have analogue document inventories and $25 \%$ have digital lists, yet $42 \%$ of funds are already partially digitised, $15 \%$ fully so. Only $2 \%$ of organisations produce detailed digital descriptions using metadata. Standards exist for storing analogue documentation in $48 \%$ of organisations, for digital data in $42 \%$, but $40 \%$ of organisations have no standards for either area. Apparently, the digitisation process is already underway, although its effectiveness will be limited if the storage and description standard is not applied. In particular, the lack of lists of documents and the disregarding of metadata description appear to be critical factors leading to inefficiencies and possible information losses. Access to documentation is also problematic, as shown in Table 1. The reason is not always a reluctance to provide documents (even if that resonates among researchers) but rather in the difficulty of finding the optimal way to achieve disclosure effectively. 
Table 2: Data types usage in Czechia based on responses to a questionnaire survey of archaeological data curators. Compiled by D. Novák

Data type

\begin{tabular}{llll} 
Raster images (JPEG, TIF, PNG...) & $13 \%$ & $7 \%$ & $80 \%$ \\
\hline Texts (PDF, DOC, DOCX, RTF...) & $12 \%$ & $9 \%$ & $79 \%$ \\
Tables (XLS, XLSX, CSV...) & $17 \%$ & $26 \%$ & $57 \%$ \\
Vector images (SVG, AI, EPS, CDR...) & $39 \%$ & $31 \%$ & $31 \%$ \\
GIS (SHP, GeoTIFF, GML, GDB...) & $41 \%$ & $32 \%$ & $28 \%$ \\
Databases (MDB, ACCDB, SQL, SIARD...) & $44 \%$ & $31 \%$ & $25 \%$ \\
CAD (DXF, DWG...) & $58 \%$ & $27 \%$ & $15 \%$ \\
3D (OBJ, PLY, BLEND, FBX...) & $57 \%$ & $32 \%$ & $11 \%$ \\
Video (MKV, MP4, AVI, MOV...) & $50 \%$ & $45 \%$ & $5 \%$ \\
Audio (WAV, MP3, OFF, FLAC...) & $69 \%$ & $28 \%$ & $3 \%$ \\
Markup (XML, HTML...) & $80 \%$ & $19 \%$ & $1 \%$
\end{tabular}

When examining the types of digital data, the spectrum of the formats is not surprising (Table 2). A positive note is that common formats prevail, i.e. text, image and spreadsheet documents, supplemented by vector graphics, GIS data and databases, which are relatively easy to handle during the archiving process (compared to 3D or audio-visual data). Data volumes mostly represent hundreds of GB to units of TB per institution (average 2.3 TB), with a total volume of archaeological field data in the whole of Czechia estimated at 200-400 TB; annual gains can be estimated at 20-30 TB (average 0.24 TB per institution). These volumes are, in principle, manageable even by the solutions offered today by the AIS CR, which already has storage and back-up capacities in the higher tens of TB.

How digital data is stored in most organisations relates to the standard of technical equipment. The most common data storage is local computer disks (61\%) and external disks $(55 \%)$. Only half of the institutions (52\%) systematically store data on network repositories, with $29 \%$ using portable media (CDs, DVDs, etc.). Only $4 \%$ of organisations use external data storage services. In $15 \%$ of cases, these data are not backed-up at all, in $34 \%$ of cases are backed-up from time-to-time, and in only $38 \%$ of cases are backedup periodically. Back-up to external media predominates (44\%), followed by back-up to network repositories (43\%); off-site network backup is undertaken by only $4 \%$ of institutions. However, the worst possible practices can be encountered - backing-up to multiple PCs (18\%) or multiple hard drives within a single PC $(6 \%)$. The use of external services (commercial and non-commercial) is entirely marginal (3\%).

The last part of our questionnaire focused on the subjectively perceived needs of organisations concerning their own archives and a willingness to work together to 
improve the situation. It is positive that $40 \%$ of institutions feel the usefulness of external assistance in the field of digitisation methodology. Hence, it is clear that at least part of the archaeological community is aware of the shortcomings of the current process through practical experience. In contrast, there was a lower demand for help in selecting data formats (27\% of institutions) and setting rules for digital repositories $(23 \%)$. The lower figures can be explained by the respondents' competence to assess the importance of the issue. Similarly, the fact that only $24 \%$ of those surveyed expressed the need for assistance with building storage capacity may be explained by good hardware equipment or by low awareness of the potential risks (only $18 \%$ of data managers are interested in cooperating on backing-up data).

The will to cooperate mostly reflects the existence of the AMCR as a central record of fieldwork events and sites, which is already running on a daily basis. There is a significantly lower willingness to cooperate in the field of digitisation (32\%), build a central register of primary documentation (26\%), centrally back-up data (17\%) and, in particular, publish data (15\%). Up to $15 \%$ of organisations are not interested in any form of cooperation with the central infrastructure. It is clear from this that further education of the professional community is needed, as, without a change of mind by researchers and data creators, no real change to the current practice can be achieved. Judging by the generally positive acceptance ( $96 \%$ of collected feedback was positive or neutral), we believe that the AIS CR infrastructure can help to initiate real improvement.

\section{A Long Way to a FAIR Environment}

Despite the issues mentioned, it is clear that after three decades of efforts to digitise and organise archaeological field data, the worst has already been overcome. At present, we can name the remaining problems, quantify their extent and seek solutions. It is crucial that on the AIS CR platform the positions and methods of the two Archaeological Institutes have been unified and coordinated at the national level.

\subsection{Changes in legislation}

The key problem today is setting up proper legislation. The current law (No. 20/1987 Coll.) needs to be substantially amended as it does not fulfil its regulatory role concerning the licensed organisations. It is required to:

- put in place an obligation to submit and centrally register fieldwork projects (written documents) according to international standards and good practice (including appropriate budgeting and avoiding price dumping);

- define the primary field documentation (including data from expert analyses) as an integral part of archaeological heritage on a similar level of protection to archaeological finds and sites;

- establish rules and fixed time limits for the submission and archiving of primary field documentation;

- set up monitoring and sanctioning mechanisms for breaches of rules and establish competent authorities to monitor compliance; 
- remove all restrictions imposed by Copyright Act to allow Open Access to archaeological archives by default;

- better specify the conditions for obtaining a licence to conduct field research and link compliance with the threat of withdrawal.

These changes may prevent the application of commercial principles within the archaeological fieldwork and put pressure on individual organisations to work in accordance with the main mission of archaeology. Both the leading archaeological institutions and some of the political representation are already becoming aware of the critical situation and the need for change. Therefore, it can be assumed that some changes may succeed in the medium term.

\subsection{New concept of the 'Excavation Report'}

The conceptual and technical nature of the ER needs to be changed. Submitting a single compiled PDF document used to be convenient in the past but ignores the possibilities of reuse that modern digital data offers. AIS CR infrastructure can provide a new concept where primary field data will be systematically collected and stored, while accompanied by formalised metadata description. The ER of the future should thus be a set of well-described and interlinked primary digital data coming from a particular field project and made available through digital infrastructure tools. This process must be done alongside a systematic widening of researcher competences and setting up proper standards.

The AIS CR infrastructure should provide a sustainable and trusted application environment based on appropriate standards and guarantee secure data storage. Given the nature of archaeological field activities and how fieldwork is organised in Czechia, we do not consider any decentralisation of data storage, e.g. on a regional basis, to be appropriate as it lies beyond the capacities of regional organisations with regard to costs and staffing requirements. On the contrary, we consider it necessary that the existing (recently launched) central AIS CR infrastructure continues to be maintained and publicly (institutionally) funded. Only a model such as this can contribute to the overall stability and predictability of the sphere of archaeological heritage management.

\subsection{Dealing with debts}

An important challenge is settling past debts, which means identifying, processing and archiving the fieldwork data not yet closed by ER, otherwise there is a real risk of a complete loss of information. This will be a long-term process which will require financial support from public budgets and is a race against time. Regardless, Czech archaeology is obliged to do its utmost in this field and not let the funds spent on fieldwork go to waste due to the dysfunctional system. In the case of larger field events, thanks to AMCR, we now have a complete list of cases that can serve as a guide for prioritising.

\section{Conclusion}

While the task of registering archaeological fieldwork in Czechia has been resolved and only part of the retrospective data is still to be compiled and registered, archiving primary field data has not yet been solved at all. Due to various reasons, data losses are high, 
and this objectively reduces the value of the fieldwork done. Owing to the AIS CR digital infrastructure, some hitherto poorly regulated processes have been channelled; stable technical, theoretical and methodological backgrounds at the national level have been set up. At the same time, centrally available data is being processed under the FAIR principles. Nevertheless, this is just the tip of the iceberg. The main goal should be to establish a deeper change in the concept of collecting data and help those organisations operating in the field to overcome traditional approaches and the backwardness of the current heritage management system. The opening of a discussion, which can be seen today, is an optimistic promise. Through enhanced contacts with the international environment and some ongoing international projects and initiatives (notably ARIADNE, SEADDA, EAC Working Groups), examples of good practice are reaching Czech archaeology. We believe that the way ahead is to further strengthen the central infrastructure and to build a competent team that can provide support for a new arrangement of the archaeological community as a whole, which fully embraces the principles of FAIR data stewardship.

\section{Acknowledgements}

This contribution was created with the support of the Archaeological Information System - Second Generation project (CZ.02.1.01/0.0/0.0/16_013/0001439), managed by the Ministry of Education, Youths and Sports of the Czech Republic and funded by the EU Structural Funds.

Kuna, M. 1994 'The State Archaeological Database' in J. Fridrich (ed) 25 Years of Archaeological Research in Bohemia, Památky archeologické - Supplementum 1. 221 28.

Kuna, M. 2002 'The archaeological record of Bohemia. An attempt at an analytical information system' in L. García Sanjuán and D. Wheatley (eds) Mapping the Future of the Past. Managing the Spatial Dimension of the European Archaeological resource, Sevilla: Universidad de Sevilla. 45-52.

Kuna, M. and Tryml, M. (eds) 2018 'Zveřejňování informací v archeologii', Zprávy památkové péče 78(1). https://zpp.npu.cz/obsahy.php?rok=2018\&cislo=1

Kuna, M., Hasil, J., Novák, D., Boháčová, I., Čulíková, L., Demján, P., Dreslerová, D., Gojda, M., Herichová, I., Křivánková, D., Lečbychová, O., Mařík, J., Maříková-Kubková, J., Panáček, M., Podliska, J., Pokorná, A., Řihošek, J., Stuchlíková, E., Suchý, M., Válek, J., Venclová, N. and Haišmanová, L. 2015 Structuring Archaeological Evidence: the archaeological map of the Czech Republic and related information systems, Prague: Institute of Archaeology CAS, Prague.

Kuna, M., Starcová, M., Maříková-Kubková, J., Blažková, G., Boháčová, I., Březinová, H., Bursák, D., Černý, V., Danielisová, A., Dobeš, M., Dreslerová, D., Gojda, M., Hasil, J., Hložek, J., Hošek, J., Chytráček, M., Ježek, M., Jiráň, L., Kapustka, K., Klápště, J., Kozáková, R., Křivánek, R., Květina, P., Kyselý, R., Limburský, P., Malyková, D., Mařík, J., Řídký, J., Salač, V., Sommer, P., Šmahelová, L., Šumberová, R., Tomanová, P., Tomková, K., Turek, J., Vencl, S., Venclová, N., Zápotocká, M. and Zápotocký, M. 
2019 Sto let $v$ archeologii. Objevy, nálezy a expedice Archeologického ústavu v Praze 1919-2019, Praha: Archeologický ústav AV ČR, Praha, v. v. i.

Perrin, K., Brown, D.H., Lange, G., Bibby, D., Carlsson, A., Degraeve, A., Kuna, M., Larsson, Y., Pálsdóttir, S.U., Stoll-Tucker, B., Dunning, C. and Rogalla von Bieberstein, A. 2014 The Standard and Guide to Best Practice in Archaeological Archiving in Europe, Namur: Europae Archaeologiae Consilium (EAC Guidelines

1). https://archaeologydataservice.ac.uk/arches/

Trtílková, I. 2020 'ESFRI Workshop - Výzkumné infrastruktury se podílejí na formování EOSCu', Velké výzkumné infrastruktury, https://www.vyzkumne-

infrastruktury.cz/2020/10/esfri-workshop-vyzkumne-infrastruktury-se-podileii-naformovani-eoscu/ [Last accessed: 13 October 2020]. 